\title{
Resumos de Teses
}

Modelo de gerenciamento da manutenção de equipamentos de radiologia convencional.

Autor: Nelson Fraga do Couto.

Orientadores: Antonio Carlos Pires Carvalho, Ana

Cecília Pedrosa de Azevedo.

Dissertação de Mestrado. UFRJ, 2002.

Foi elaborado um modelo de gerenciamento da manutenção dos equipamentos convencionais de raios $\mathrm{X}$ no Hospital Universitário Clementino Fraga Filho. 0 modelo foi implementado em várias etapas, que incluíram visitas a centros hospitalares que gerenciam seus equipamentos, linha de colaboração com a Fundação Instituto Oswaldo Cruz para a realização de cursos e treinamento de técnicos de eletrônica do hospital, montagem de uma esquemateca dos equipamentos em uso, criação de um programa de gerenciamento utilizando um banco de dados na plataforma Microsoft Windows 98 Access, levantamento operacional e condições de funcionamento dos equipamentos

A criação de uma nova rotina nas manutenções vai de encontro às necessidades de se reduzir o tempo de atendimento, os custos e a melhoria na qualidade da imagem em um serviço de radiodiagnóstico, atendendo também às exigências da Portaria no $\mathbf{4 5 3 / 9 8}$ do Ministério da Saúde.

Elaboração de um programa de monitoração ocupacional em radiologia para o Hospital Universitário Clementino Fraga Filho.

Autor: Sergio Ricardo de Oliveira.

Orientadores: Ana Cecília Pedrosa de Azevedo, Antonio Carlos Pires Carvalho.

Dissertação de Mestrado. UFRJ, 2002.

Foi elaborado um programa de monitoração ocupacional em radiologia médica para o Hospital Universitário Clementino Fraga Filho da Universidade Federal do Rio de Janeiro, seguindo as normas e legislações nacionais. Para a construção do programa foi necessária a realização de um levantamento prévio de todos os Serviços e funcionários que estavam diretamente expostos às radiações ionizantes. Foi diagnosticado que a maioria desses funcionários não era monitorada, apenas três serviços mantinham um controle de dose de trabalhadores com contratos de prestação de serviço independentes e que não havia controle para os casos de doses elevadas. Com a implantação do programa de monitoração ocupacional, os passos seguintes foram: a contratação da uma nova empresa que prestasse o serviço de monitoração pessoal, reduzindo significativamente o custo anual de operação com o contrato único para o hospital; a inclusão de mais sete serviços que trabalham com radiações ionizantes, aumentando em mais de $60 \%$ o número de trabalhadores monitorados; o controle de doses elevadas, principalmente no setor de hemodinâmica, que apresentou a maior média de dose, de 0,32 $\mathrm{mSv} / \mathrm{mês}$; e a monitoração de área, que foi realizada em períodos intercalados nos pontos considerados de maior risco para a população e os trabalhadores.

Paralelamente, o programa de monitoração ocupacional foi informatizado, sendo construído um banco de dados com o propósito de controlar e armazenar as doses funcionais. Com a implantação do programa, começa-se a compreender os riscos de se trabalhar com radiações ionizantes, a partir dos conceitos de proteção radiológica, e conscientiza-se quanto ao uso correto dos monitores de dose. 